NATIONAL LABORATORY

MANAGED BY UT-BATTELLE FOR THE DEPARTMENT OF ENERGY
Energy \& Transportation Science Division

\author{
CRADA Final Report \\ For \\ CRADA Number \\ ORNL00-0605
}

Josh Pihl, Brian West, Todd Toops

Oak Ridge National Laboratory
Brad Adelman, Ed Derybowski Navistar, Inc.

\section{Advanced Engine/Aftertreatment System R\&D}

\author{
Prepared by \\ Oak Ridge National Laboratory \\ Oak Ridge, TN 37831 \\ managed by \\ UT-BATTELLE, LLC \\ for the \\ U.S. Department of Energy \\ under contract DE-AC05-00OR22725
}

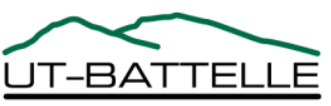

ORNL-27 (4-00)
Approved for Unlimited Release 


\section{DOCUMENT AVAILABILITY}

Reports produced after January 1, 1996, are generally available free via the U.S. Department of Energy (DOE) Information Bridge.

Web site http://www.osti.gov/bridge

Reports produced before January 1, 1996, may be purchased by members of the public from the following source.

National Technical Information Service

5285 Port Royal Road

Springfield, VA 22161

Telephone 703-605-6000 (1-800-553-6847)

TDD 703-487-4639

Fax 703-605-6900

E-mail info@ntis.gov

Web site http://www.ntis.gov/support/ordernowabout.htm

Reports are available to DOE employees, DOE contractors, Energy Technology Data Exchange (ETDE) representatives, and International Nuclear Information System (INIS) representatives from the following source.

Office of Scientific and Technical Information

P.O. Box 62

Oak Ridge, TN 37831

Telephone 865-576-8401

Fax 865-576-5728

E-mail reports@osti.gov

Web site http://www.osti.gov/contact.html

This report was prepared as an account of work sponsored by an agency of the United States Government. Neither the United States Government nor any agency thereof, nor any of their employees, makes any warranty, express or implied, or assumes any legal liability or responsibility for the accuracy, completeness, or usefulness of any information, apparatus, product, or process disclosed, or represents that its use would not infringe privately owned rights. Reference herein to any specific commercial product, process, or service by trade name, trademark, manufacturer, or otherwise, does not necessarily constitute or imply its endorsement, recommendation, or favoring by the United States Government or any agency thereof. The views and opinions of authors expressed herein do not necessarily state or reflect those of the United States Government or any agency thereof. 


\title{
CRADA FINAL REPORT FOR CRADA NUMBER ORNL00-0605
}

\section{ADVANCED ENGINE/AFTERTREATMENT SYSTEM R\&D}

\author{
Josh Pihl, Brian West, Todd Toops \\ Oak Ridge National Laboratory \\ Brad Adelman, Ed Derybowski \\ Navistar, Inc.
}

Date Published: September, 2011

\author{
Prepared by \\ OAK RIDGE NATIONAL LABORATORY \\ Oak Ridge, Tennessee 37831-6283 \\ managed by \\ UT-BATTELLE, LLC \\ for the \\ U.S. DEPARTMENT OF ENERGY \\ under contract DE-AC05-00OR22725
}





\section{CONTENTS}

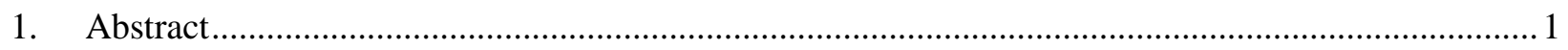

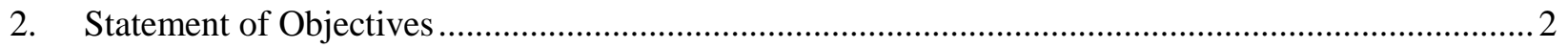

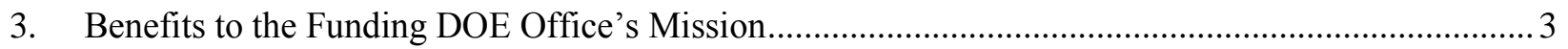

4. Technical Discussion of Work Performed by All Parties ............................................................... 3

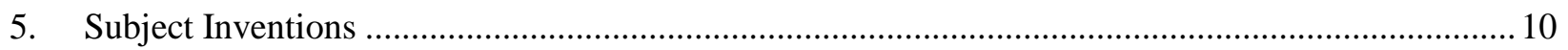

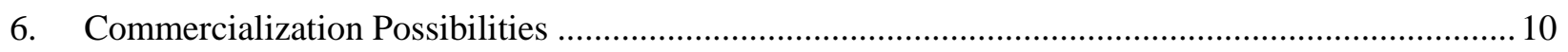

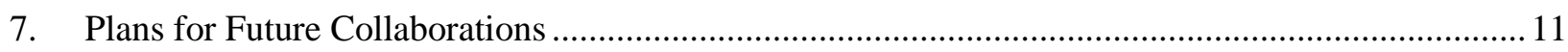

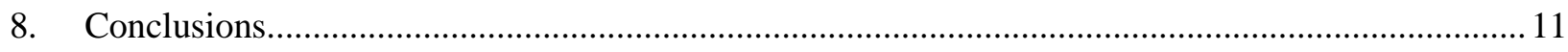

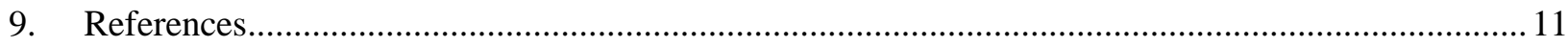




\section{ABSTRACT}

Navistar and ORNL established this CRADA to develop diesel engine aftertreatment configurations and control strategies that could meet emissions regulations while maintaining or improving vehicle efficiency. The early years of the project focused on reducing the fuel penalty associated with lean NOx trap (LNT, also known as NOx adsorber catalyst)) regeneration and desulfation. While Navistar pursued engine-based (in-cylinder) approaches to LNT regeneration, complementary experiments at ORNL focused on in-exhaust fuel injection. ORNL developed a PC-based controller for transient electronic control of EGR valve position, intake throttle position, and actuation of fuel injectors in the exhaust system of a Navistar engine installed at Oak Ridge. Aftertreatment systems consisting of different diesel oxidation catalysts (DOCs) in conjunction with a diesel particle filter and LNT were evaluated under quasi-steady-state conditions. Hydrocarbon (HC) species were measured at multiple locations in the exhaust system with Gas chromatograph mass spectrometry (GC-MS) and Fourier transform infrared (FTIR) spectroscopy.

Under full-load, rated speed conditions, injection of fuel upstream of the DOC reduced the fuel penalty for a given level of NOx reduction by 10-20\%. GC-MS showed that fuel compounds were "cracked" into smaller hydrocarbon species over the DOC, particularly light alkenes. GC-MS analysis of HC species entering and exiting the LNT showed high utilization of light alkenes, followed by mono-aromatics; branched alkanes passed through the LNT largely unreacted. Follow-on experiments at a "road load" condition were conducted, revealing that the NOx reduction was better without the DOC at lower temperatures. The improved performance was attributed to the large swings in the NOx adsorber core temperature.

Split-injection ${ }^{1}$ experiments were conducted with ultra-low sulfur diesel fuel and three pure HC compounds: 1-pentene, toluene, and iso-octane. The pure compound experiments confirmed the previous results regarding hydrocarbon reactivity: 1-pentene was the most efficient LNT reductant, followed by toluene. Injection location had minimal impact on the reactivity of these two compounds. Iso-octane was an ineffective LNT reductant, requiring high doses (resulting in high $\mathrm{HC}$ emissions) to achieve reasonable NOx conversions. Diesel fuel reactivity was sensitive to injection location, with the best performance achieved through fuel injection downstream of the DOC. This configuration generated large LNT temperature excursions, which probably improved the efficiency of the NOx storage/reduction process, but also resulted in very high $\mathrm{HC}$ emissions.

The ORNL team demonstrated an LNT desulfation under "road load" conditions using throttling, EGR, and in-pipe injection of diesel fuel. Flow reactor characterization of core samples cut from the front and rear of the engine-aged LNT revealed complex spatially dependent degradation mechanisms. The front of the catalyst contained residual sulfates, which impacted NOx storage and conversion efficiencies at high temperatures. The rear of the catalyst showed significant sintering of the washcoat and precious metal particles, resulting in lower NOx conversion efficiencies at low temperatures.

Further flow reactor characterization of engine-aged LNT core samples established that low temperature performance was limited by slow release and reduction of stored NOx during regeneration. Carbon monoxide was only effective at regenerating the LNT at temperatures above $200^{\circ} \mathrm{C}$; propene was unreactive even at $250^{\circ} \mathrm{C}$. Low temperature operation also resulted in unselective NOx reduction, resulting in high emissions of both $\mathrm{N}_{2} \mathrm{O}$ and $\mathrm{NH}_{3}$.

During the latter years of the CRADA, the focus was shifted from LNTs to other aftertreatment devices. Two years of the CRADA were spent developing detailed ammonia SCR device models with sufficient

\footnotetext{
${ }^{1}$ Reductant spray into the exhaust was split, with fuel spray both upstream and downstream of the DOC.
} 
accuracy and computational efficiency to be used in development of model-based ammonia injection control algorithms. ORNL, working closely with partners at Navistar and Michigan Technological University (MTU), developed a flow reactor experimental protocol designed to measure critical parameters needed for model development, calibration, and validation. These included $\mathrm{NH}_{3}$ storage capacities, $\mathrm{SCR}$ reactions rates, and $\mathrm{NH}_{3}$ and $\mathrm{NO}$ oxidation rates over a wide range of temperatures, space velocities, and gas compositions. The resulting data sets were transferred to MTU, where Navistar's partners used them to calibrate and validate their models.

To determine the impact of aging on key model parameters, ORNL also exercised the experimental protocol on catalyst samples aged on an engine dynamometer by Navistar. Two distinct aging mechanisms were observed from these experiments: hydrothermal sintering of the catalyst washcoat components, and deposition of precious metals volatilized from an upstream diesel oxidation catalyst (DOC).

Near the end of the CRADA, the technology focus was shifted to diesel particulate filters (DPFs). This shift was a logical consequence of Navistar's strategic decision to utilize in-cylinder NOx control, precluding a current need for NOx aftertreatment. In-cylinder NOx control places more of a demand on the DPF due to increased particulate production and/or reduced passive filter regeneration by NOx. If not managed carefully, the resulting higher soot loading rates would require more frequent active regeneration events to avoid excessive filter backpressure or runaway regenerations, thereby increasing the fuel penalty associated with the DPF. The goal of the final phase of the project was to improve the fidelity of DPF regeneration models so they could be used to identify fuel optimal control strategies. Navistar obtained miniature DPFs with several different formulations from suppliers, loaded the filters in engine exhaust, and shipped them to ORNL, where carefully controlled DPF regeneration experiments were conducted. Temperature programmed oxidations revealed complex variations in soot oxidation rate and pressure drop evolution, which could be explained, in part, by spatial variations in the regeneration process. Pulsed oxidation experiments were employed to measure soot oxidation kinetics as a function of temperature, gas composition, and burnout for both active and passive regeneration. Navistar utilized the data sets from these experiments to calibrate their DPF regeneration models.

\section{STATEMENT OF OBJECTIVES}

The overall goal of the CRADA was to develop diesel engine/aftertreatment system configurations and control strategies that meet stringent emissions regulations while improving overall vehicle efficiency. The focus of the CRADA research shifted to different aftertreatment component technologies as the regulatory landscape and Navistar's strategies evolved. The specific CRADA objectives for each aftertreatment technology were as follows:

LNT:

- Develop LNT regeneration and desulfation strategies for diesel aftertreatment systems.

- Improve the effectiveness and efficiency of LNTs by understanding the role and fate of various hydrocarbon species in LNT regeneration through engine experiments.

- Define pathways to reduce catalyst deactivation and fuel penalty from sulfation and desulfation processes by examining fully-formulated engine-aged LNT catalysts in flow reactors.

- Identify factors limiting NOx conversion during low-temperature operation with $\mathrm{CO}$ and hydrocarbon reductants. 
SCR:

- Develop a transient evaluation protocol for ammonia selective catalytic reduction (SCR) catalysts that generates data sets sufficient for control model development, parameter estimation, and validation.

- Quantify the impacts of engine-aging on key catalyst parameters needed for control models through protocol experiments.

DPF:

- Enhance the fundamental understanding of diesel particulate filter (DPF) operating principles to facilitate fuel-optimal control strategy formulation.

- Develop experimental methods that probe the underlying chemical kinetics and changes in soot reactivity under carefully controlled DPF regeneration conditions.

- Measure the reaction kinetics and operating parameters of DPFs needed to develop accurate simulation tools and effective control strategies.

\section{BENEFITS TO THE FUNDING DOE OFFICE'S MISSION}

Diesel engines serve as the prime movers of our nation's commercial transportation infrastructure, and account for a significant fraction of our total petroleum consumption. Moreover, diesels and other lean burn engine technologies offer a promising pathway for reducing the fuel consumption of the light duty vehicle fleet. However, meeting increasingly stringent emissions regulations in the lean exhaust of diesel engines has proven challenging. The engine modifications and aftertreatment systems used to reduce exhaust emissions typically increase fuel consumption, eroding the inherent efficiency advantages of diesel engines.

Development of diesel engine systems that meet stringent emissions standards while improving overall vehicle efficiency requires careful optimization of the entire engine/aftertreatment system. The CRADA pursued two complementary paths toward this goal: evaluation of aftertreatment configurations and associated control strategies, and measurement of aftertreatment device parameters required for development of simulation tools used in control algorithm design and optimization. The insights and simulation tools that followed from the work under the CRADA will help Navistar bring to market high efficiency engine systems that reduce fuel consumption while complying with emissions regulations. These engines could substantially reduce petroleum consumption from commercial vehicles, and provide a pathway to improve the efficiency of the light duty fleet. Such outcomes directly support the mission of the Office of Energy Efficiency and Renewable Energy's Vehicle Technologies Program, which is "to develop more energy efficient and environmentally friendly highway transportation technologies that enable America to use less petroleum."

\section{TECHNICAL DISCUSSION OF WORK PERFORMED BY ALL PARTIES}

FY2002

The first several years of the CRADA focused on engine-based investigations of regeneration and desulfation strategies for lean NOx trap (LNT) catalysts (also known as NOx adsorber catalysts). The Navistar/ORNL CRADA team decided to investigate two parallel pathways to achieving the fuel-rich conditions needed to release and reduce stored NOx and remove sulfur from the catalyst. Navistar 
pursued late-cycle, in-cylinder injection of fuel, while ORNL focused on in-manifold (before the turbo) and in-pipe (after the turbo) fuel injection.

Much of the first year of the project was spent setting up the necessary experimental systems. Navistar provided a production T444e diesel engine which was installed in an ORNL engine test cell with a motoring dynamometer with digital transient control. The ORNL team developed a PC-based system for transient electronic control of EGR valve position, intake throttle position, and actuation of fuel injectors in exhaust manifold and downstream pipe locations. They also fabricated the first aftertreatment system for evaluation, which consisted of a diesel oxidation catalyst, a catalyzed diesel particulate filter, and a lean NOx trap. The ORNL team demonstrated better than $90 \%$ NOx reduction under steady-state modes for the first engine/aftertreatment system configuration.

\section{FY2003}

During the second year of the CRADA, the ORNL team focused on engine experiments conducted at full load, rated speed ( $450 \mathrm{ft}-\mathrm{lb}, 2300 \mathrm{RPM}, \sim 600^{\circ} \mathrm{C}$ catalyst temperatures) with three different aftertreatment configurations. The first configuration consisted of a catalyzed diesel particulate filter upstream of the LNT. The second and third configurations included diesel oxidation catalysts of two different sizes ( 2.5 liter or 5.0 liter) upstream of the CDPF. An LNT regeneration strategy was developed that achieved $70 \%$ $\mathrm{NOx}$ reduction at the rated power condition while still maintaining $\mathrm{CO}$ and $\mathrm{HC}$ emissions below mandated not-to-exceed (NTE) levels. By varying in-pipe fuel injection rates for the three configurations, the ORNL team showed that the presence of the upstream oxidation catalyst reduced the amount of fuel required to achieve comparable NOx reduction by $10-20 \%$. The total fuel penalty for LNT operation was less than $2.5 \%$.

Gas chromatograph mass spectrometry (GC-MS) and Fourier transform infrared (FTIR) spectroscopy were used to quantify the hydrocarbon species entering and exiting the NOx adsorber catalyst to better understand the exhaust chemistry during LNT regeneration. The detailed hydrocarbon measurements revealed that a substantial amount of fuel cracking (splitting of the relatively large fuel constituent hydrocarbons into smaller, lighter compounds) occurred over the oxidation catalysts, generating relatively high concentrations of light alkenes (propene, butenes, and pentenes). Comparing LNT inlet and outlet $\mathrm{HC}$ measurements, it became apparent that these light alkenes were readily utilized by the LNT for NOx release and reduction. The higher reactivity of these cracked HCs explained the reduced fuel penalty for the configurations containing a DOC. Looking at other classes of HCs, mono-aromatics were also found to be relatively reactive over the LNT, while branched alkanes were not consumed as readily by the LNT.

\section{FY2004}

Navistar continued to investigate in-cylinder approaches to LNT regeneration, while the ORNL team members extended the studies of in-pipe fuel injection to include lower temperature "road load" (200 ft$\mathrm{lb}, 1800 \mathrm{RPM}, \sim 400^{\circ} \mathrm{C}$ catalyst temperatures) operation. Concerns about fuel evaporation and mixing at this lower temperature operating point led the ORNL team to develop an air-assisted fuel injector, which greatly improved atomization. The air-assisted injector improved fuel cracking over the DOC, generating more than twice as much butene as the conventional injector. Use of the air-assisted injector at the full load, rated speed condition reduced fuel consumption by about 5-8\% while maintaining the same NOx reduction efficiency. Better than $80 \%$ NOx reduction was achieved under road load conditions, in spite of the catalyst suffering from sulfur poisoning due to extended engine-exhaust operation on ultra-low sulfur diesel fuel.

Two of the previously investigated aftertreatment system configurations were evaluated at the road load operating condition: the CDPF + LNT only configuration, and the configuration with a large upstream 
DOC. While the DOC once again generated a significant amount of cracked fuel products, the system without a DOC actually provided equivalent NOx reduction at a lower fuel penalty.

Several factors could have contributed to the more efficient operation without a DOC for this operating point, including LNT temperature profiles and exhaust chemistry differences. Since diesel engine exhaust contains excess oxygen, injection of fuel into the exhaust pipe upstream of a catalyst generates a significant exotherm within the catalyst as the fuel reacts with the remaining oxygen. For the aftertreatment configuration with an upstream DOC, this exotherm occurs within the DOC, and the LNT temperature stays fairly constant. However, in the absence of a DOC, the exotherm occurs inside the LNT itself, resulting in fairly large temperature swings. While the cycle-averaged LNT temperature for the two cases is the same, the exotherm results in a lower temperature during NOx storage and a higher temperature during regeneration. Temperature impacts LNT performance by changing reaction rates and stability of the stored NOx. The lower temperature during storage increases the effective LNT storage capacity, allowing for longer times between regeneration events. The higher temperature during regeneration decreases the stability of the stored NOx, resulting in more complete regeneration of the storage sites. Together, these temperature effects could reduce the amount of fuel required to achieve a given NOx conversion over the LNT. As previously discussed, the DOC also alters the exhaust chemistry. In addition to cracking fuel compounds into lighter $\mathrm{HCs}$, the DOC will consume any $\mathrm{CO}$ in the engine exhaust. In the absence of a DOC, CO was measured at the LNT inlet. Since CO is known to be an effective reductant for LNT regeneration, it may have improved the regeneration efficiency.

\section{FY2005}

In an attempt to decouple the effects of reductant chemistry and LNT temperature under road load conditions, the ORNL team modified the engine experiment setup to enable fuel injection both upstream and downstream of the DOC. This split injection strategy allowed the bulk of the exotherm associated with oxygen depletion to occur in the DOC, keeping the LNT temperature relatively constant, and allowed uncracked hydrocarbons to be used in the regeneration (the CDPF had minimal effect on the exhaust HC speciation).

Split-injection experiments were conducted with ultra-low sulfur diesel fuel and three pure HC compounds: 1-pentene (a light alkene), toluene (a mono-aromatic), and 2,2,4-trimethylpentane (isooctane, a branched alkane). The pure compound experiments confirmed the previous results regarding reactivity of the various hydrocarbon species: when comparing NOx reduction normalized to equivalent fuel penalties, 1-pentene was the most efficient LNT reductant, followed by toluene. Iso-octane was fairly unreactive over the LNT. Achieving reasonable NOx conversion efficiencies required high dosing rates of iso-octane, resulting in a large fuel penalty and excessive $\mathrm{HC}$ emissions.

Injection location (DOC inlet or outlet or split injection) had very little effect on the reactivity of pentene or toluene. Conversely, using diesel fuel as the reductant resulted in a very high sensitivity to injection location, with the best performance being achieved with injection of the fuel downstream of the DOC. As expected, this configuration generated large LNT temperature excursions as observed in the previous year's experiments, which probably improved the efficiency of the NOx storage/reduction process. However, injection of diesel downstream of the DOC also resulted in very high $\mathrm{HC}$ emissions.

The ORNL team also developed a protocol for an LNT desulfation under "road load" conditions using throttling, EGR, and in-pipe injection of diesel fuel. 
During 2006, the CRADA team focused on more detailed characterization of the LNT catalyst that was used for engine experiments during the previous years of the project. Core samples were cut from the front and rear faces of the LNT and analyzed with several techniques to measure the effects of thermal aging and sulfur poisoning on catalyst properties and performance. Nitrogen physisorption measurements showed that the specific surface area at the front of the LNT was approximately $30 \%$ more than the specific surface area at the rear of the LNT. X-ray diffraction measurements indicated that the precious metal particles at the rear of the catalyst were more sintered by thermal aging than those at the front. Both of these observations indicate more thermal aging occurred at the rear of the LNT brick than at the front. This non-uniform aging was likely a result of engine experiments where reductant was injected downstream of the DOC, generating significant exotherms within the LNT catalyst. During the desulfation experiment, for example, the temperature at the rear of the catalyst was at least $50^{\circ} \mathrm{C}$ higher than at the front of the catalyst. The higher temperatures at the rear of the catalyst induced more sintering of the catalyst washcoat, reducing surface area and increasing precious metal particle size.

Diffuse reflectance infrared Fourier transform spectroscopy (DRIFTS) experiments revealed a substantial amount of sulfur at the front face of the catalyst, while no sulfur was observed on the rear of the catalyst. The NOx storage capacity of the front sample, as measured in a micro-reactor under simulated exhaust conditions, was much lower than the capacity of the rear sample at temperatures near the upper end of the LNT operating window. The limited storage capacity at the front of the catalyst is consistent with the presence of sulfur, which strongly binds to the storage sites and prevents NOx uptake.

Together, these observations highlight how operation under engine exhaust conditions can generate complicated non-uniform aging within an aftertreatment catalyst. This point is further evidenced by micro-reactor measurements of NOx conversion under lean/rich cycling: the front of the catalyst showed superior NOx conversion at the lower temperature, while the rear sample was better at the higher temperature. At low temperatures, LNT catalyst performance is typically limited by the activity of the precious metal catalysts in oxidation of $\mathrm{NO}$ to $\mathrm{NO}_{2}$ during the storage phase and/or reduction of the stored NOx during regeneration. Since the front face of the catalyst had a higher surface area and higher precious metal dispersion, it retained a higher level of activity at low temperature. At high temperatures, LNT performance is limited by the stability of the stored nitrates (that is, the storage capacity). Under these conditions, the front of the LNT brick suffered from the sulfur on the catalyst surface; the sulfurfree rear of the LNT catalyst retained a higher level of NOx conversion. In all, the inhomogeneous changes in the engine-operated catalyst performance and properties highlighted the difficulty of understanding, predicting, and mitigating catalyst aging under real-world operation.

\section{FY2007}

Continuing the emphasis on flow reactor characterization of LNT catalysts, the CRADA team focused on developing a better understanding of the factors that limit low-temperature performance. Navistar provided catalyst core samples that were cut from engine-aged LNTs. ORNL installed the core samples in a flow reactor and conducted a series of experiments designed to examine the effects of temperature, space velocity, lean/rich cycle duration, and reductant speciation on overall NOx conversion, reductant consumption, and product selectivity.

As expected, catalyst performance fell off sharply at low temperatures. Using $\mathrm{CO}$ as the primary reductant species, NOx conversion dropped at temperatures below $250^{\circ} \mathrm{C}$, with a particularly steep decline between 225 and $200^{\circ} \mathrm{C}$. Low temperature performance limitations in LNT catalysts are often attributed to slow $\mathrm{NO}$ oxidation kinetics, as the incoming $\mathrm{NO}$ must be converted to $\mathrm{NO}_{2}$ to achieve efficient $\mathrm{NOx}$ storage. However, $\mathrm{NO}_{2}$ was observed at the catalyst outlet even at the lowest temperatures, 
indicating NO oxidation activity was not limiting the LNT performance. More detailed analysis of the flow reactor data revealed that there was actually significant NOx uptake at the onset of low temperature cycling, but after several cycles NOx storage diminished. The reductant species were apparently unable to release and reduce the stored NOx during the rich phase of the operating cycle at low temperatures, and the NOx storage sites were quickly saturated. Thus, it was the inability of the precious metal to activate the reductant species and catalyze the NOx release/reduction process that limited low temperature performance.

In addition to NOx conversion, the low temperatures affected $\mathrm{CO}$ conversion and regeneration product selectivity. CO conversion followed a similar trend to NOx conversion: it remained relatively high at $250^{\circ} \mathrm{C}$, but dropped substantially as the temperature was reduced. For all of the conditions tested, the LNT catalyst generated a mixture of product species, including $\mathrm{N}_{2}, \mathrm{NH}_{3}$, and $\mathrm{N}_{2} \mathrm{O}$.

Space velocity had less of an impact than temperature on catalyst performance. NOx conversion did not appear to follow any trends with space velocity. $\mathrm{CO}$ conversion decreased with increasing space velocity. Product selectivity also shifted: higher space velocities generated more $\mathrm{NH}_{3}$ and less $\mathrm{N}_{2} \mathrm{O}$.

Reductant speciation was perhaps the most important factor for determining catalyst performance. Switching from $\mathrm{CO}$ to propene $\left(\mathrm{C}_{3} \mathrm{H}_{6}\right)$ dropped NOx conversion by more than half. Propene is a light alkene, a class of compounds shown to be very effective at LNT regeneration in engine experiments. The previous engine experiments, however, were conducted at much higher catalyst temperatures. Propene (and likely any other hydrocarbon) is not sufficiently reactive to be an effective LNT reductant at low temperatures.

\section{FY2008}

During 2008, the focus of the CRADA was shifted from LNTs to $\mathrm{NH}_{3}$ selective catalytic reduction (SCR) catalysts. Navistar had been working with collaborators at Michigan Technological University to create an SCR simulation tool with sufficient accuracy and computational efficiency to be used in model-based ammonia control system design. Such tools require model parameter calibration with data sets collected under relevant operating conditions. The CRADA partners decided to focus on generating the required data sets using flow reactor experiments. To this end, ORNL, Navistar, and MTU worked together to develop an experimental protocol that captured the critical parameters needed to accurately model SCR catalysts. These parameters included: $\mathrm{NH}_{3}$ storage capacity, $\mathrm{NO}$ oxidation rates, $\mathrm{NH}_{3}$ oxidation rates, and SCR reaction rates under multiple inlet gas compositions. The protocol was designed to measure these parameters over a wide range of temperatures and space velocities.

Navistar obtained a zeolite SCR catalyst sample from a supplier and shipped a core sample to ORNL, where it was loaded into a flow reactor. Preliminary runs with the protocol indicated that completing all of the planned experiments would require over 500 hours of reactor operating time. Limited project resources and reactor availability made such a large effort impractical if experiments were only run during normal business hours. To overcome this issue, the ORNL team set up a fully automated flow reactor designed to operate unattended over nights and weekends.

\section{FY2009}

After running preliminary experiments in 2008, the CRADA team further refined the $\mathrm{NH}_{3} \mathrm{SCR}$ experimental protocol to ensure it provided the essential data for model calibration and validation. The rest of the year was spent running the protocol over a range of temperatures $\left(150-550^{\circ} \mathrm{C}\right)$, space velocities $\left(60,000,90,000\right.$, and 120,000 $\left.\mathrm{hr}^{-1} \mathrm{GHSV}\right)$, and reactant concentrations $(150,300$, and $450 \mathrm{ppm} \mathrm{NOx})$ and analyzing the resulting data sets. 
The protocol steps included measurements under SCR reaction conditions with different $\mathrm{NO}_{2} / \mathrm{NOx}$ and $\mathrm{NH}_{3} / \mathrm{NOx}$ ratios. Like many SCR catalysts, the NOx conversion performance was extremely sensitive to the $\mathrm{NO}_{2} / \mathrm{NOx}$ ratio of the inlet gas. The highest conversions were achieved with equimolar mixtures of $\mathrm{NO}$ and $\mathrm{NO}_{2}$. Performance dropped off as the feed composition was shifted to an excess of either NOx species. Interestingly, the material we conducted our experiments showed higher rates of reaction with $\mathrm{NO}_{2}$ only than with $\mathrm{NO}$ only at all temperatures. Varying the $\mathrm{NH}_{3} / \mathrm{NOx}$ ratio also yielded interesting results. At high temperatures, increasing the $\mathrm{NH}_{3}$ resulted in higher NOx conversions, as expected. However, at low temperatures, the opposite trend was observed: increasing $\mathrm{NH}_{3}$ dose reduced $\mathrm{NOx}$ conversion, consistent with $\mathrm{NH}_{3}$ inhibition of the SCR reaction at low temperature. Both of these insights (higher $\mathrm{NO}_{2}$ reaction rates and $\mathrm{NH}_{3}$ inhibition) were shared with our MTU modeling collaborators, who made appropriate modifications to their model.

In addition to the steady state data typically collected for evaluation of SCR catalysts, the experiment protocol included three steps designed to probe the amount and stability of $\mathrm{NH}_{3}$ stored on the catalyst surface: (1) $\mathrm{NH}_{3}$ adsorption, (2) isothermal desorption, (3) and temperature programmed desorption (TPD). For adsorption temperatures above $300^{\circ} \mathrm{C}$, all of the $\mathrm{NH}_{3}$ was released during the isothermal desorption step prior to the TPD. For adsorption temperatures below $300^{\circ} \mathrm{C}$, the amount of $\mathrm{NH}_{3}$ desorbed during the TPD increased with decreasing adsorption temperature, consistent with expected increase in NH3 storage capacities with decreasing temperature. For all but one of the TPD runs, there was a single $\mathrm{NH}_{3}$ desorption feature centered at approximately $300^{\circ} \mathrm{C}$. At $150^{\circ} \mathrm{C}$ there was a second low temperature $\mathrm{NH}_{3}$ desorption, likely due to formation of ammonium nitrates on the catalyst surface.

Besides the isothermal and temperature programmed desorption steps, the protocol included two other measurements of $\mathrm{NH}_{3}$ storage capacity: $\mathrm{NH}_{3}$ uptake under inert conditions and consumption of $\mathrm{NO}$ by stored $\mathrm{NH}_{3}$ after the $\mathrm{NH}_{3}$ feed was shut off. With the exception of the lowest temperature run, the three storage capacities are fairly consistent across the three measurement techniques. Based on this observation, we concluded that a measurement of $\mathrm{NH}_{3}$ storage capacity can be achieved through any of the three techniques for temperatures above $200^{\circ} \mathrm{C}$. At lower temperatures, the slow SCR kinetics limited the $\mathrm{NOx}$ reacted with stored $\mathrm{NH}_{3}$. The appropriate measure of $\mathrm{NH}_{3}$ storage capacity would therefore depend on the application of the measurement.

All of the protocol experiment data sets were transferred to our modeling collaborators at MTU. They employed selected segments of the test protocol to isolate global kinetic parameters. After calibrating the kinetic parameters, they used the full transient data sets for model validation.

The CRADA team also conducted the experimental protocol on engine-aged catalyst samples to see how the measured reaction kinetics and storage capacities degraded with catalyst aging. Navistar provided two catalyst monoliths removed from the exhaust system of an engine that had been run extensively on a dynamometer. Core samples were cut from the front face and back face of the first SCR monolith. The protocol experiments revealed two separate aging mechanisms that impacted catalyst performance. At low temperatures, both core samples suffered a similar drop in $\mathrm{NO}$ and $\mathrm{NH}_{3}$ conversion, likely due to loss of active catalyst surface area from hydrothermal aging mechanisms (washcoat sintering, zeolite dealumination, or loss of exchanged metal cations from the zeolite structure). In addition to the loss of low temperature performance, the front face core sample showed a drop in NOx conversion accompanied by an increase in $\mathrm{NH}_{3}$ conversion under SCR conditions at high temperatures. The drop in SCR performance was caused by an order of magnitude increase in the rate of $\mathrm{NH}_{3}$ oxidation by $\mathrm{O}_{2}$ (compared to the unaged catalyst). The most likely explanation for such a large increase in $\mathrm{NH}_{3}$ oxidation is deposition of precious metals volatilized from the upstream DOC onto the front face of the SCR catalyst. 
During FY2010 the focus of the CRADA shifted from ammonia selective catalytic (SCR) systems to diesel particulate filters (DPFs). The goal of this new phase of the project was to measure relevant soot oxidation kinetics that would be integrated into Navistar's DPF regeneration control models. Due to the complexities inherent in engine experiments, the CRADA team decided to conduct our kinetic measurements on a bench-scale flow reactor system at ORNL. Navistar identified several DPF formulations of interest and obtained miniature $(2.5 \mathrm{~cm}$ outer diameter by $7.6 \mathrm{~cm} \mathrm{long})$ particulate filter samples from suppliers. The formulations were based on three different substrate materials: cordierite, aluminum titanate, and silicon carbide. Half of the filters were washcoated with an oxidation catalyst; the other half were left uncoated. The filters were loaded with soot in an engine exhaust slip stream at a Navistar engine testing partner facility. The filters were subsequently sent to ORNL for detailed characterization of the regeneration process in an automated flow reactor. Flow reactor experiments conducted in FY2010 focused on temperature programmed oxidations (TPOs). The TPO experiments consisted of loading a miniature DPF in the reactor, heating it to $200^{\circ} \mathrm{C}$, starting the flow of a known composition of oxidant $\left(\mathrm{O}_{2}, \mathrm{NOx}\right.$, or a mixture of the two ) through the filter, and linearly increasing the filter temperature to $650^{\circ} \mathrm{C}$. These controlled burnout experiments allowed characterization of soot oxidation rates and pressure drop evolution over the course of a complete regeneration.

Soot oxidation rates as a function of temperature were calculated based on $\mathrm{CO}$ and $\mathrm{CO}_{2}$ evolved during the $\mathrm{O}_{2}$ TPO experiments on all six DPF formulations. To account for variations in total soot loading, the oxidation rates were normalized to the initial amount of soot on the fully loaded filter. The resulting oxidation rate profiles were very similar for all three substrate materials in the absence of a catalytic washcoat. This result was expected since, in the absence of a catalyst, the oxidation kinetics should be determined primarily by the properties of the soot, and all of the soot samples were collected under very similar engine operating conditions. Measurable oxidation by $\mathrm{O}_{2}$ was observed at around $300^{\circ} \mathrm{C}$, but the reaction rate did not become significant until around $450^{\circ} \mathrm{C}$. The peak burnout rate occurred at $600^{\circ} \mathrm{C}$, after which the rapidly decreasing amount of soot on the filter caused a drop in $\mathrm{CO}$ and $\mathrm{CO}_{2}$ evolved. The washcoat resulted in a slight increase in oxidation rate over the entire regeneration for cordierite and aluminum titanate, resulting in slightly lower peak burnout temperatures than for the uncatalyzed substrates. Interestingly, the presence of the washcoat on the silicon carbide substrate appeared to have a slightly negative impact on $\mathrm{O}_{2}$ oxidation kinetics over the entire regeneration. The difference between the catalyzed and uncatalyzed silicon carbide filters was small, but the catalyst definitely did not have the positive impact on $\mathrm{O}_{2}$ oxidations kinetics as seen in the other two substrate materials. It should be noted that this result was not confirmed with a replicate run due to a limited number of available samples. The lack of apparent catalytic activity may have been due to a problem with the catalytic coating or some undetermined error in the reactor run.

As expected, inclusion of $\mathrm{NO}_{\mathrm{x}}$ in the feed gas substantially increased the soot oxidation rate at low temperatures; measurable oxidation was observed as low as $200^{\circ} \mathrm{C}$. As in the $\mathrm{O}_{2}$ TPOs, the burnout curves for the uncatalyzed filters were fairly similar, but the presence of a catalytic washcoat introduced substantial differences between the substrate materials. In this case, the oxidation catalyst significantly increased the low temperature oxidation rates for all the substrates. Further, unlike the fairly simple burnout curves observed for the $\mathrm{O}_{2}$ TPOs, the catalytic coating resulted in fairly complex $\mathrm{NOx}+\mathrm{O}_{2}$ oxidation rate behavior that changed significantly with substrate material. The burnout profile, which contained multiple peaks in reaction rate as a function of temperature, suggested that different types of soot (or soot environments) existed within the filter.

Since the washcoat composition and loading were nominally the same for the three substrates, the differences in oxidation kinetics were most likely due to variations in washcoat location and distribution, which were caused by differences in substrate microstructure (porosity, monolith geometry, and affinity 
for the washcoat material). These variations in the washcoat could, in turn, have resulted in different soot distributions within the filter (more soot in the cake layer as opposed to within the filter wall, for example).

Further evidence of possible spatial variations in soot loading and oxidation behavior could be seen in the filter backpressure evolution during the regeneration. For all of the formulations and operating conditions investigated, the filter pressure drop decreased to that of a clean filter by the time half of the soot had been oxidized. This observation highlighted the inadequacy of pressure sensors for determining filter regeneration status: the pressure sensor would indicate a complete regeneration long before all of the soot in the filter has actually been consumed. It also illustrated the complex spatial dependence of the soot oxidation process. The soot that created most of the filter pressure drop (located within the filter wall, for example) burned out faster than the soot located elsewhere. This effect was magnified when NOx was added to the feed gas: the backpressure drops after only a third of the soot had been oxidized. Why the NOx was more selective in burning out the soot contributing to the backpressure (even in the absence of a catalytic coating) remains unclear.

Comparison of the oxidation rates with different oxidant mixtures $\left(\mathrm{O}_{2}, \mathrm{NOx}\right.$, or $\left.\mathrm{O}_{2}+\mathrm{NOx}\right)$ demonstrated the synergistic effect of $\mathrm{O}_{2}$ and $\mathrm{NOx}$ over a catalyzed filter. On the uncatalyzed filter, the oxidation rate for the $\mathrm{O}_{2}+\mathrm{NOx}$ experiment was roughly the sum of the runs with $\mathrm{O}_{2}$ and NOx individually. However, on the catalyzed sample, the $\mathrm{O}_{2}+\mathrm{NOx}$ TPO showed a substantially increased low temperature soot oxidation rate over either the individual catalyzed $\mathrm{O}_{2}$ and NOx experiments or the uncatalyzed $\mathrm{O}_{2}+\mathrm{NOx}$ TPO. The increase in low temperature oxidation rate was likely due to catalytic oxidation of $\mathrm{NO}$ to $\mathrm{NO}_{2}$, a more reactive species for carbon oxidation. The $\mathrm{O}_{2}+\mathrm{NOx}$ feed gas also resulted in a drop in backpressure at a much lower fractional soot burnout than in cases with just $\mathrm{O}_{2}$ or $\mathrm{NOx}$, implying that $\mathrm{NO}_{2}$ was more selective in burning soot located in the filter wall.

FY2011

The TPO experiments conducted in 2010 yielded interesting insights on soot reactivity trends and pressure drop evolution. However, DPF regeneration model parameter calibration required experimental data collected under more carefully controlled conditions. To this end, the ORNL team conducted a series of pulsed oxidation experiments to measure soot oxidation kinetics as a function of temperature, gas composition, and soot burnout. A method was also developed for probing active oxygen surface area with oxygen chemisorption. Rate parameters were extracted from these experiments for use in DPF regeneration model development.

\section{SUBJECT INVENTIONS}

No inventions were filed under this CRADA.

\section{COMMERCIALIZATION POSSIBILITIES}

The insights and simulation tools that followed from the work under the CRADA will help Navistar bring to market high efficiency engine systems that reduce fuel consumption while complying with emissions regulations. 


\section{PLANS FOR FUTURE COLLABORATIONS}

Navistar and ORNL have an existing contract in place for evaluation of advanced aftertreatment catalysts, and are in continuing conversations over future collaboration opportunities. Navistar has also provided loaded DPF samples for use in neutron imaging experiments under a separate DOE-funded project.

\section{CONCLUSIONS}

The Navistar/ORNL CRADA generated new information regarding diesel engine aftertreatment configurations and operating strategies, as well as data sets appropriate for aftertreatment device model parameter calibration. These insights were integrated into Navistar's simulation toolset for use in designing fuel-optimal control strategies for high efficiency engine/aftertreatment systems.

\section{REFERENCES}

Annual reports to U.S. Department of Energy Vehicle Technologies Program: http://www1.eere.energy.gov/vehiclesandfuels/resources/fcvt_reports.html

B.H. West, J.F. Thomas, M. Kass, J.M. Storey, and S.L. Lewis, "NOx Adsorber Regeneration Phenomena in Heavy-Duty Applications," U.S. Department of Energy Advanced Combustion Engines Merit Review, Argonne, IL, May 13-15, 2003.

B.H. West, J.F. Thomas, M. Kass, J.M. Storey, S.L. Lewis, "NOx Adsorber Regeneration Phenomena In Heavy Duty Applications: ORNL/ ITEC CRADA," presented at 9th Diesel Engine Emissions Reduction Workshop, August 2003.

B.H. West, T.J. Toops, J.A. Pihl, "ITEC CRADA-Advanced Engine/Aftertreatment System Research and Development", DOE-Advanced Combustion Engine Program Annual Merit Review, Crystal City, VA, May 2007.

J.A. Pihl, T.J. Toops, "ITEC CRADA-Advanced Engine/Aftertreatment System Research and Development", DOE-Advanced Combustion Engine Program Annual Merit Review, Crystal City, VA, February 2008.

J.A. Pihl, T.J. Toops, V.O. Strots, E.M. Derybowski, "Development and Implementation of Experimental Protocol for Steady-State and Transient SCR Kinetics," $12^{\text {th }}$ DOE Crosscut Workshop on Lean Emissions Reduction Simulation Workshop, Dearborn, MI, April 28, 2009.

J.A Pihl, T.J. Toops, V.O. Strots, E.M. Derybowski, "NOx Abatement Research and Development CRADA with Navistar Incorporated," 2009 DOE Vehicle Technologies Merit Review, Arlington, VA, May 21, 2009.

J.A Pihl, T.J. Toops, V.O. Strots, E.M. Derybowski, “Advanced Engine/Aftertreatment System R\&D CRADA with Navistar Incorporated," 2010 DOE Vehicle Technologies Program Annual Merit Review \& Peer Evaluation Meeting, Washington, DC, June 10, 2010. 
J.A. Pihl, T.J. Toops, V.O Strots, S.B. DeLand, G.G. Parker, J.H. Johnson, “Development \& Implementation of Experimental Protocol for Steady-State and Transient SCR Kinetics," 2009 American Institute of Chemical Engineers Annual Meeting, Nashville, TN, November 12, 2009. 


\begin{tabular}{l} 
Final Report Certification \\
for \\
CRADA Number $\quad$ ORNL00-0605 \\
\hline
\end{tabular}

Between

UT-Battelle, LLC

and

Navistarin inc.

(Participant)

\section{Instructions:}

Mark the appropriate statement in 1a or $1 \mathrm{~b}$ below with an "IX." Refer to the articles in the CRADA terms and conditions governing the identification and marking of Protected CRADA Information (PCl).

If no $\mathrm{PCl}$ is identified, the report will be distributed without restriction. If $\mathrm{PCl}$ is identified, the report distribution will be limited in accordance with the CRADA terms and conditions governing release of data. In all cases items 2 and 3 must be true. That is, the report cannot contain Proprietary Information and a disclosure must be filed prior to release of the report.

This certification may either be made by using this form or may be made on company letterhead if the Participant desires. A faxed copy of this completed form is acceptable.

The following certification is made for the subject final report:

1. (a) $\square$ The final report contains information that qualifies as "Protected CRADA Information" $(\mathrm{PCl})$. The $\mathrm{PCl}$ legend is printed on the report cover, and the $\mathrm{PCl}$ is clearly identified.

OR

(b) ХThe final report does not contain "Protected CRADA Information." The "Approved for Public Release" legend is printed on the report cover.

2. The final report does not contain Proprietary Information.

3. By the signature below, the Participant has no objection to the public distribution of the final report due to patentable information.

For the Participant:

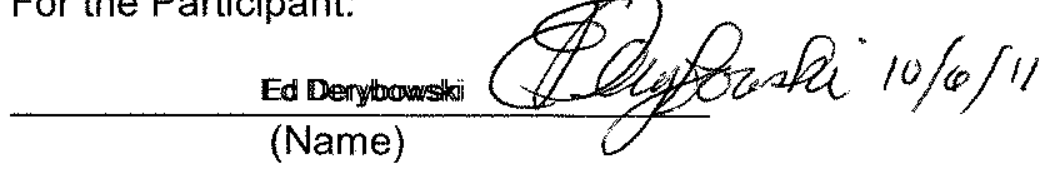

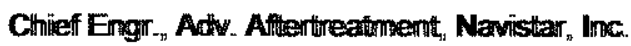

(Title) 